\title{
Pengaruh Penambahan Fly Ash Terhadap Perilaku Teknis Tanah Ekspansif di Daerah Selimau Kabupaten Bulungan
}

\author{
Fuad Harwadi*1, Sepri Rantesalu ${ }^{2}$, Nofrizal ${ }^{3}$ \\ ${ }^{1}$ Program Studi Teknik Sipil, FT-UBT, Tarakan \\ ${ }^{1,2,3}$ Program Studi Teknik Sipil, FT-UNIKALTAR, Tanjung Selor
}

E-mail: *11 fuadharwadi@gmail.com, ${ }^{2}$ sepry77@gmail.com, ${ }^{3}$ nofrizal020481@gmail.com

Received 23 November 2020; Reviewed 19 February 2021; Accepted 28 April 2021

Journal Homepage: http://jurnal.borneo.ac.id/index.php/borneoengineering

\begin{abstract}
Expansive soil is one of the problematic soils for civil engineering construction. The high swelling-shrinkage nature results in deformations that can damage the construction on it, therefore it is necessary to make improvements in expansive soil. One of the most widely used methods of improving expansive soil is stabilization using chemical additives. In this research using coal waste material (fly ash) as stabilizer from PLTU Sekayan in Kaltara Province, so it can be said as environmentally friendly stabilization. The research objective was to determine changes in engineering behavior of expansive soil through compaction tests and CBR. The test results will be displayed in graphical form, namely by comparing the expansive soil that has not been stabilized (initial conditions) and the expansive soil that has been stabilized with fly ash at mixed variations of 20\%, 30\% and 40\%, and has passed the curing period for 5, 15, and 30 days. From this research, it was found that the addition of a stabilizer (fly ash) could improve its engineering properties, and the optimum results were obtained at the addition of $40 \%$ fly ash and after 30 days of curing time. From the compaction test, it was found that the volume weight of dry soil $\left(\gamma_{\text {dry }}\right)$ increased by $14.05 \%$ from $1.21 \mathrm{gr} / \mathrm{cm}^{3}$ to $1.38 \mathrm{gr} / \mathrm{cm}^{3}$ and the optimum water content $\left(w_{\text {opt }}\right.$ ) decreased by $38.12 \%$ from $31.19 \%$ to $19,3 \%$. From CBR testing in the laboratory, there was a very large increase in the value of $C B R_{\text {Design }}$ namely $2192 \%$ from $0.72 \%$ to $16.5 \%$.
\end{abstract}

Keywords: expansive soil; fly ash additional; engineering behavior.

\begin{abstract}
Abstrak
Tanah ekspansif adalah merupakan salah satu jenis tanah bermasalah bagi konstruksi teknik sipil. Sifat kembang-susut yang tinggi mengakibatkan deformasi yang bisa merusak konstruksi yang ada diatasnya, oleh karena itu perlu dilakukan usaha perbaikan pada jenis tanah seperti ini. Salah satu metode perbaikan tanah ekspansif yang banyak dilakukan adalah dengan cara stabilisasi menggunakan tambahan bahan kimia. Pada penelitian ini menggunakan bahan limbah abu terbang batu bara dari PLTU Sekayan yang ada Provinsi Kaltara sebagai bahan stabilisasinya, sehingga dapat dikatakan sebagai stabilisasi yang ramah lingkungan. Tujuan penilitian diharapakan dapat melihat perubahan perilaku teknis tanah ekspansif melalui uji pemadatan dan CBR laboratorium. Hasil pengujian akan ditampilkan dalam bentuk grafik yaitu dengan membandingkan antara tanah ekspansif yang belum distabilisasi (kondisi awal) dan tanah ekspansif yang sudah distabilisasi dengan fly ash pada variasi campuran 20\%, 30\% dan $40 \%$, serta telah melewati masa peram selama 5 hari, 15 hari dan 30 hari. Dari penelitian ini didapatkan bahwa penambahan bahan stabilisasi berupa fly ash dapat meningkatkatkan sifat teknisnya, dan hasil optimum diperoleh pada penambahan fly ash $40 \%$ dan setelah melewati masa peram 30 hari. Dari pengujian pemadatan didapatkan peningkatan berat volume tanah kering $\left(\gamma_{\text {dry }}\right)$ sebesar $14,05 \%$ dari $1,21 \mathrm{gr} / \mathrm{cm} 3 \mathrm{menjadi} 1,38 \mathrm{gr} / \mathrm{cm} 3 \mathrm{dan}$ kadar air optimum $\left(w_{\text {opt }}\right.$ ) turun 38,12\% dari 31,19\% menjadi 19,3\%. Dari pengujian CBR di laboratorium terjadi peningkatan nilai $C_{B R}$ Desain yang sangat besar yaitu sebesar $2192 \%$ dari kondisi awal 0,72\% menjadi $16,5 \%$.
\end{abstract}

Kata kunci: tanah ekspansif; penambahan fly ash; sifat teknis. 


\section{Pendahuluan}

Tanah ekspansif atau sering juga disebut tanah mengembang adalah istilah yang digunakan pada material tanah yang mempunyai potensi pengembangan (swelling) dan penyusutan (shrinkage) yang tinggi oleh pengaruh perubahan kadar air, sehingga mengakibatkan terjadinya perubahan volume tanah yang cukup besar juga. Jenis tanah yang mudah berubah volumenya ini adalah tanah yang banyak mengandung lempung (Hardiyatmo, 2014), sehingga sering juga disebut tanah lempung ekspansif. Identifikasi tanah ekspansif ada 3 (tiga) cara, yaitu identifikasi mineralogi, cara tidak langsung dan cara pengukuran langsung (Chen, 1975 dalam Hardiyatmo, 2014). Indikator tanah ekspansif dapat diketahui melalui alat X-RD (X-Ray Diffractometer) yang digunakan untuk mendeteksi kandungan mineral tanah lempungnya. Apabila banyak terdapat mineral montmorillonite maka tanah tersebut bisa dikategorikan sebagai tanah lempung ekspansif (Gunarso A., 2017). Dan cara paling sederhana untuk mengetahui tanah ekspansif adalah menggunakan korelasi batas-batas Atterberg, yaitu dengan indikasi tingginya nilai plastisitas indeks (Sudjianto, 2015)

Adanya sifat dari tanah lempung ekspansif tersebut sering menimbulkan kerusakan pada bangunan seperti retaknya dinding dan lantai hingga pondasi, sedangkan pada jalan raya mulai retak memanjang hingga retak longitudinal. (Sudjianto, 2014), hal ini disebabkan karena pada saat tanah lempung mengembang dapat meningkatkan tekanan pengembangan. Pada saat mengembang dan menyusut terjadi perubahan volume yang signifikan, perubahan volume tersebut mengakibatkan naik-turunnya permukaan tanah, dimana hal ini yang dapat mengakibatkan kerusakan pada konstruksi bangunan yang ada diatasnya. Sehingga dalam dunia konstruksi diperlukan upaya perbaikan (soil improvement) apabila akan melaksanakan pembangunan infrastruktur diatas tanah lempung ekspansif.

Topik penelitian ini dipilih karena dampak tanah ekspasif yang sangat membahayakan bagi konstruksi yang ada diatasnya khususnya konstruksi dengan pondasi dangkal dan konstruksi jalan raya, selain itu peneliti juga akan memanfaatkan limbah fly ash dari PLTU Sekayan sebagai bahan stabilisasi karena kondisi saat ini belum banyak yang memanfaatkan limbah fly ash yang ada di Kabupaten Bulungan Provinsi Kalimantan Utara tersebut. Tanah lempung ekspansif diambil yang ada disekitar Kota Tanjung Selor. Kedepannya dengan penelitian ini diharapkan dapat mengatasi 2 (dua) permasalahan sekaligus, yaitu permasalahan pada tanah lempung ekspansif dan juga permasalahan limbah abu terbang batubara (fly ash) dari PLTU.

Kelebihan dalam penelitian ini selain inovasi pembangunan yang ramah lingkungan (environmentally friendly), juga terdapat beberapa perbedaan dengan kebanyakan penelitianpenelitian sebelumnya, yaitu :

1. Pencampuran bahan stabilisasi (fly ash) dengan tanah ekspansif dilakukan dalam kondisi tanah basah agar lebih mendekati kondisi tanah asli dilapangan;

2. Dalam penelitian ini menggunakan variasi masa peram yang lebih lama, dengan pertimbangan bahwa proses stabilisasi kimiawi memerlukan waktu untuk proses pengikatan yang cukup lama dan hasil evaluasi penelitian-penelitian sebelumnya menunjukan kencendrungan yang terus meningkat;

3. Prosentase penambahan fly ash lebih dari penelitian-penelitian sebelumnya karena melihat kecendrungan dari kurva/grafik yang dihasilkan terus meningkat.

Tujuan yang ingin dicapai dalam penelitian ini adalah untuk mengetahui seberapa besar pengaruh perubahan sifat teknis tanah ekspansif yang sudah distabilisasi dengan fly ash dan untuk mengetahui pada penambahan fly ash berepa persen tercapai peningkatan kekuatan optimum serta pada masa peram berapa lama terjadi peningkatan kekuatan optimum, yang diamati dari parameter-parameter teknis tanah ekspansif tersebut. 


\section{Metode Penelitian}

Data penelitian berupa data primer dan sekunder. Data primer meliputi : Data-data yang diperoleh hasil uji yang dilakukan di laboratorium. Data sekunder meliputi : data penunjang yang bisa mendukung data primer seperti data kandungan kimia bahan abu terbang batubara (fly ash) yang diperoleh dari PT. Sumber Alam Sekurau selaku Pengelola PLTU Sekayan Desa Apung Kabupaten Bulungan. Tahapan dalam penelitian ini dapat dilihat dalam bentuk diagram alir penelitian seperti yang ditunjukan pada Gambar 1 .

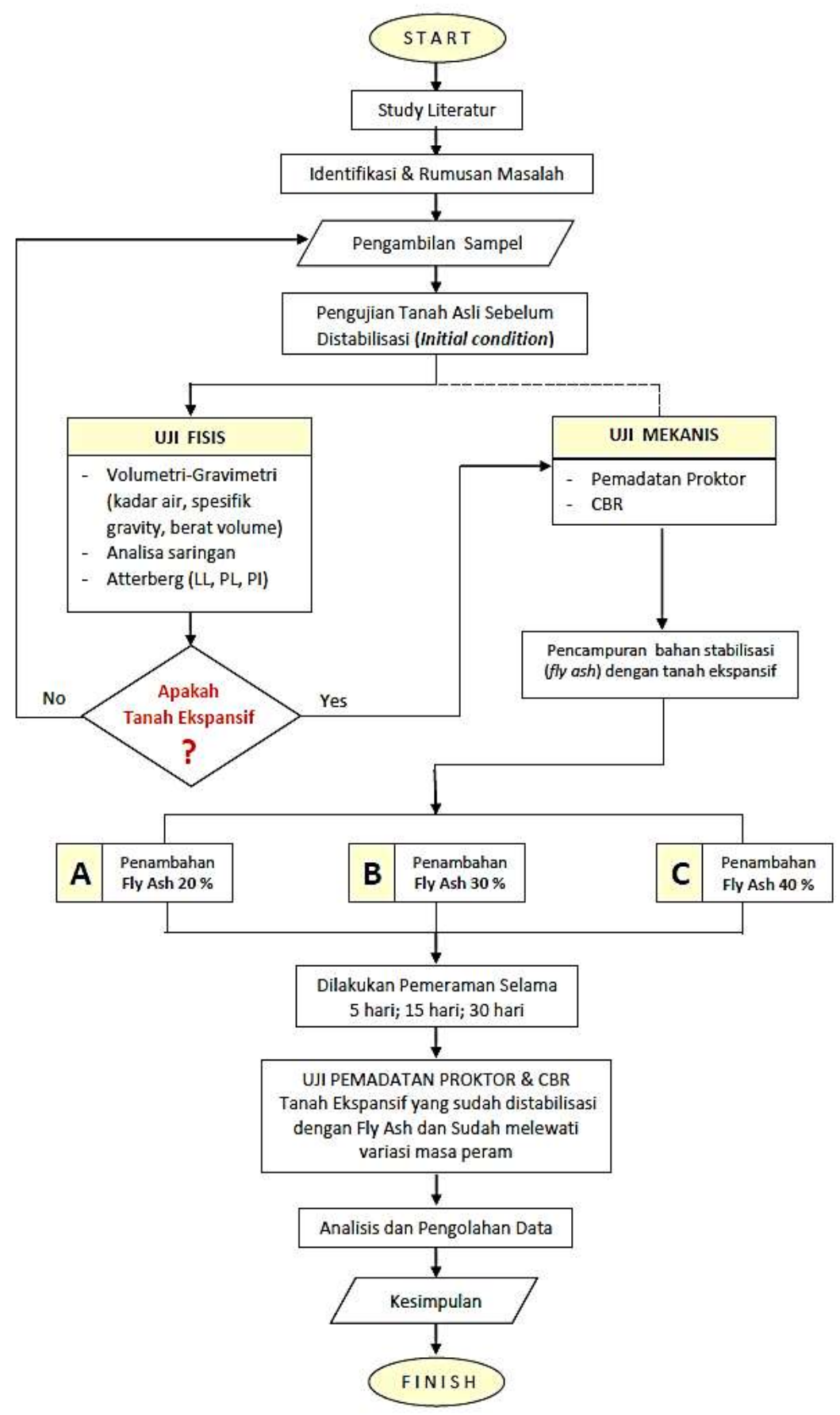

Gambar 1. Diagram Alir Penelitian 


\subsection{Dasar Penentuan Campuran}

Penentuan besarnya campuran dan lamanya masa peram pada penelitian ini berdasarkan hasil pengamatan dan analisa hasil penelitian sebelumnya yang dilakukan oleh Budi S.G (2003), Herman (2013)(2014), I Gusti Agung (2014), Denny dkk., (2016), Ermawan dkk., (2018) dan Walewangko (2020). Dimana dari grafik dari hasil pengujian di laboratoriumnya memperlihatkan kecendrungan (trend) yang terus meningkat, oleh karena itu peneliti mencoba melakukan penambahan komposisi campuran dan masa peramnya.

\subsection{Parameter dan Standar Pengujian}

Dalam penelitian ini dilakukan pengujian parameter fisik dan parameter mekanis tanah asli (sebelum distabilisasi) dan tanah lempung ekspansif yang sudah distabilisasi.

Paremeter sifat fisik yang diuji diantaranya kadar air (SNI-1965-2008), specific gravity (SNI 1964:2008), berat volume tanah (SNI 02-3637-1994), analisa saringan (SNI 3423:2008), batas cair (SNI 1967:2008), batas plastis (SNI 1966:2008).

Parameter sifat teknis yang diperoleh dari pengujian mekanis diantaranya uji pemadatan proktor (SNI 1742:2008) yang mendapatkan parameter berat volume tanah kering dan kadar air optimum, uji CBR Laboratorium (SNI 1744:2012). Sayangnya beberapa pengujian teknis lainnya tidak dapat dilakukan, seperti uji konsolidasi dan kekuatan geser, berhubung kondisi peralatan laboratorium yang sudah tidak memenuhi syarat karena belum dikalibrasi lagi.

\section{Hasil dan Pembahasan}

\subsection{Pengujian Sifat Fisis Tanah Asli}

Kadar Air $\left(\boldsymbol{w}_{c}\right)$. Dari pengujian kadar air tanah ekspansif yang berpedoman pada SNI-1965-2008 diperoleh nilai kadar air sebesar $72,10 \%$ dimana pada saat pengambilan sampel dalam kurung waktu satu minggu sebelumnya tidak terjadi intensitas hujan yang cukup besar. Hal ini menunjukan bahwa tanah tersebut merupakan tanah lunak yang memiliki rongga (voids) yang cukup besar yang terisi oleh air dan udara.

Specific Gravity (Gs). Pengujian ini bertujuan untuk menentukan kepadatan massa butiran atau partikel tanah yaitu perbandingan antara berat butiran tanah dan berat air suling dengan volume yang sama pada suhu tertentu. Pengujian berdasarkan SNI 1964:2008 diperoleh nilai specific gravity tanah ekspansif asli adalah sebesar 2,54.

Berat Volume Tanah $(\gamma)$. Mengacu pada SNI 02-3637-1994 pengujian berat volume tanah asli untuk mengetahui perbandingan antara berat dengan volume tanah. Dari hasil pengujian di Daerah Selimau memiliki nilai berat volume tanah lempung ekspansif sebesar $1,59 \mathrm{gr} / \mathrm{cm}^{3}$.

Analisa Saringan. Untuk melihat ukuran butiran dan penggolongan jenis tanah digunakan pengujian ukuran butiran menggunakan saringan sesuai SNI 3423:2008. Berdasarkan uji analisa saringan diketahui bahwa 63,91\% lolos saringan nomor 200. Berdasarkan klasifikasi AASHTO maupun USCS tanah sampel ini merupakan katagori tanah berbutir halus, yaitu bisa tanah lempung (clay) dan bisa tanah lanau (silt) tergantung nilai plastisitasnya.

Uji Konsistensi (Atterberg). Tanah yang berbutir halus biasanya memiliki sifat plastis. Sifat plastis tersebut merupakan kemampuan tanah menyesuaikan perubahan bentuk tanah setelah bercampur dengan air pada volume yang konstan tanpa retak-retak dan remuk. Batas Atterberg memperlihatkan terjadinya bentuk tanah dari benda padat hingga menjadi cairan kental sesuai 
dengan kadar airnya. Dari uji ini akan didapatkan parameter batas cair $(\boldsymbol{L L})$, batas plastis $(\boldsymbol{P L})$, dan indeks plastis (PI) yang merupakan keadaan konsistensi tanah. Pengujian batas cair mengacu pada SNI 1967:2008 diperoleh nilai batas cair tanah lempung ekspansif di Daerah Selimau adalah sebesar 52,039 \% dan pengujian batas plastis dengan berpedoman pada SNI 1966:2008 diperoleh nilai sebesar $32,32 \%$.

Dari nilai batas cair dan batas plastis dapat diketahui nilai indeks plastis (PI) adalah sebesar LL PL, yaitu sebesar 19,72\%. Berdasarkan nilai batas cair (LL) dan indeks plastis (PI) maka jenis tanah berbutir halusnya sudah bisa diketahui dengan menggunakan diagram plastisitas USCS seperti yang ditunjukan pada Gambar 2.

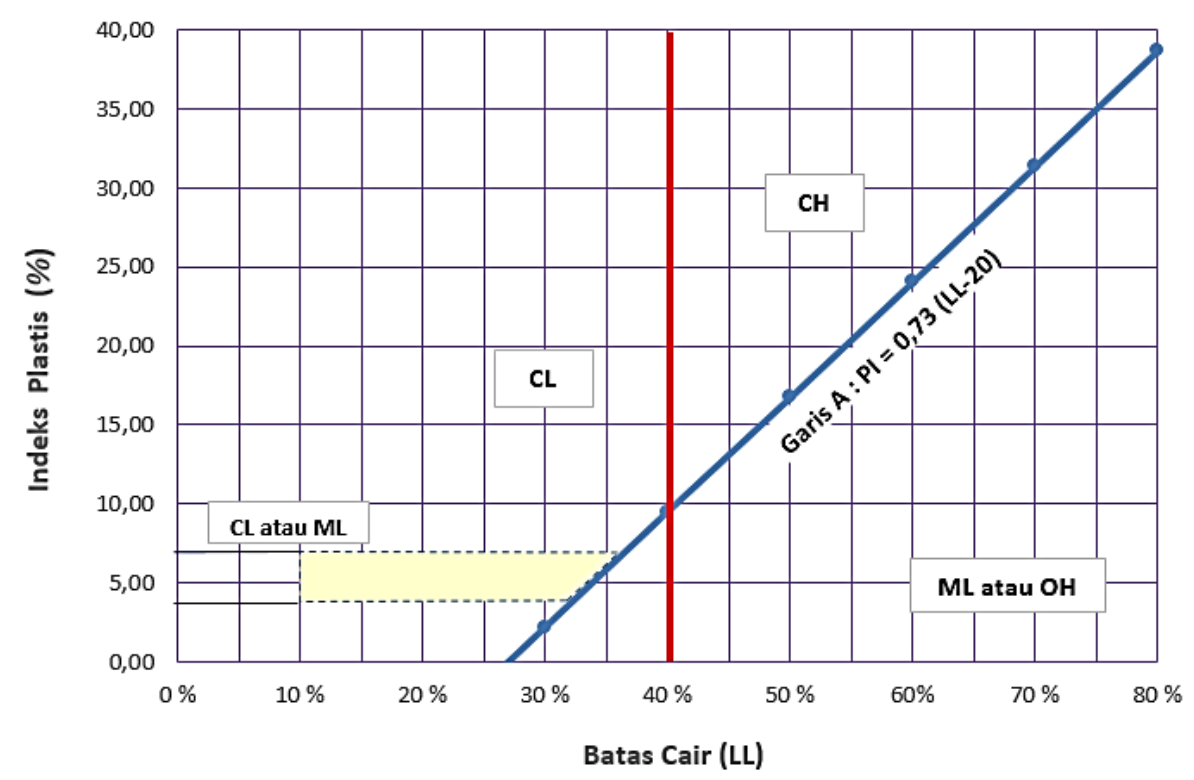

Gambar 2 Diagram Platisitas USCS

Berdasarkan diagram plastisitas USCS seperti yang ditunjukan pada Gambar 2 dapat diketahui bahwa jenis tanah asli sebagai bahan penelitian ini adalah termasuk kedalam klasifikasi tanah $\mathrm{CH}$, yaitu tanah lempung dengan plastisitas cukup sedang. Dan dengan nilai indeks plastis (PI) sebesar 19,72\% maka berdasarkan ASTM D-1883 maka tanah di Daerah Selimau Kabupaten Bulungan dapat digolongkan sebagai tanah ekspansif, karena menurut ASTM D-1883 salah satu indikator tanah ekspansif apabila indeks plastis $>10 \%$.

\subsection{Pengujian Sifat Mekanis}

Untuk melihat perilaku teknis tanah lempung ekspansif, maka perlu dilakukan uji mekanis berupa uji pemadatan proktor dan CBR di laboratorium. Pengujian ini dilakukan pada tanah asli (sebelum ditambahkan fly ash) dan pengujian pada tanah lempung ekspansif yang sudah distabilisasi dengan penambahan fly ash berbagai komposisi campuran ( 20\%,30\% dan 40\%) serta setelah melewati masa peram selama 5 hari, 15 hari dan 30 hari. Dari uji pemadatan proktor diperoleh 2 (dua) parameter, yaitu berat volume kering $\left(\gamma_{d r y}\right)$ dan kadar air optimum $\left(w_{\text {opt }}\right)$. Pengujian CBR laboratorium menggunakan CBR terendam (soaked) dan hasilnya dikonverikan dalam bentuk $\mathrm{CBR}_{\text {Desain }}$

\subsubsection{Uji Sifat Mekanis Tanah Asli (Initial condition)}

Uji Pemadatan Standar Proktor. Dengan mengacu pada SNI 1742:2008 pengujian pemadatan standar proktor dimaksudkan untuk menentukan hubungan antara kadar air dan kepadatan tanah 
yang dipadatkan di dalam sebuah cetakan berukuran tertentu dengan penumbuk $2,5 \mathrm{~kg}$ yang dijatuhkan secara bebas dari ketinggian $305 \mathrm{~mm}$. Cara uji ini mencakup ketentuan-ketentuan mengenai peralatan, cara pengujian dan contoh uji, cara pengerjaan, perhitungan, dan pelaporan. Dari pengujian di laboratorium diperoleh hasil yang dituangkan dalam bentuk grafik seperti yang ditunjukan pada Gambar 3.

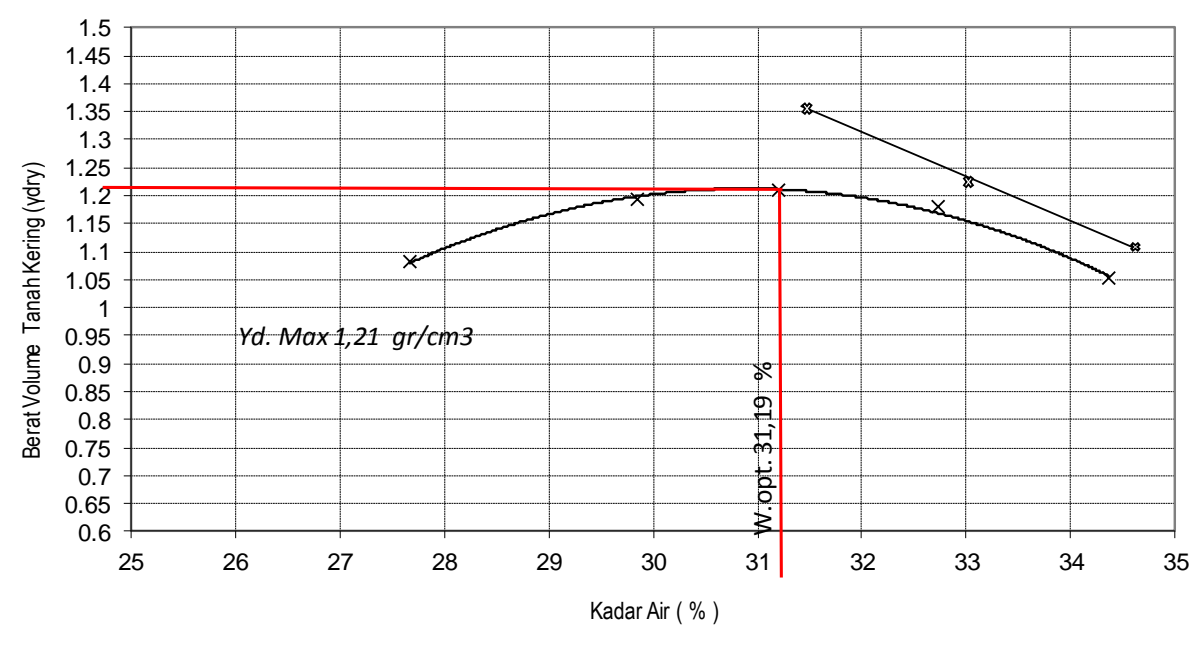

Gambar 3 Grafik Hubungan Antara Kadar Air dan Berat Volume Tanah Kering

Dari Gambar 3 hasil pengujian pemadatan tanah standar proktor diperoleh nilai berat isi kering maksimum $\left(\gamma_{\text {dry maks. }}\right.$ ) sebesar $1.21 \mathrm{gr} / \mathrm{cm}^{3}$, dan berat kadar air rata - rata optimum $\left(w_{\text {opt }}\right)$ sebesar $31.19 \%$. Berdasarkan referensi penelitian-penelitian sebelumnya tentang tanah ekspansif, nilai berat volume tanah kering maksimum ( $\gamma$ dry maks.) berkisar sekitar antara 1,2 $-1,3 \mathrm{gr} / \mathrm{cm} 3 \mathrm{dan}$ kadar air optimum $\left(\mathrm{w}_{\mathrm{opt}}\right)$ berada pada sekitar $15-35 \%$.

Uji CBR Laboratorium. Tujuan pengujian ini adalah untuk menilai kekuatan tanah dasar (subgrade) yang dikompaksi di laboratorium (SNI 1744:2012) yang akan digunakan dalam perencanaan tebal perkerasan (pavement) jalan dinyatakan sebagai nilai CBR dari Laboratorium (dalam \%) akan dikonvesri menjadi $\mathrm{CBR}_{\text {Desain }}($ dalam \%) sesuai untuk kebutuhan perencanaan tebal perkerasan jalan. Penentuan $\mathrm{CBR}_{\text {Desain }}$ berdasarkan garfik hubungan antara nilai CBR Laboratorium pada pemadatan 10, 25, 56 pukulan (blows) pad sumbu absis dan nilai kepadatan tanah kering $\left(\gamma_{d r y}\right)$ pada sumbu ordinat, kemudian menghubungkan nilai kepadatan kering maksimum $\left(\gamma_{\text {dry }}\right.$ maks. $)$ berdasarkan uji standar proktor sampai mengenai kurva, dan menarik garis kebawah (sumbu absis) untuk melihat nilai $\mathrm{CBR}_{\text {Desain }}$ yang dimaksud. Berdasarkan hasil pengujian CBR di laboratorium diperoleh nilai $\mathrm{CBR}_{\text {Desain }}$ tanah asli (yang belum distabilisasi) adalah $0.72 \%$. Nilai ini menunjukan daya dukung tanah dasar tanah asli (sebelum distabilisasi) masih sangat lemah dan tidak bisa langsung digunakan sebagai tanah dasar konstruksi jalan tetapi harus dilakukan perbaikan tanah (soil improvement) terlebih dahulu.

\subsubsection{Indikator Tanah Ekspansif Setelah Distabilisasi}

Dari pengujian tanah ekpansif yang sudah distabilisasi dengan fly ash sebesar 20\%, 30\% dan $40 \%$ dan setelah melewati masa peram 5 hari, 15 hari dan 30 hari memperlihatkan penurunan nilai indeks plastis $(P I)$.

Gambar 4 memperlihatkan pengaruh penambahan stabiliser (FA) terhadap nilai indeks plastis. Dari hasil tersebut memperlihatkan bahwa semakin banyak fly ash yang ditambahkan semakin menurunkan nilai indeks plastis (PI). Hal ini disebabkan terserapnya air dalam proses kimiawi (pozzolanic) antara fly ash dan tanah lempung ekpansif dan proses fisika yaitu fly ash mengisi 
rongga pori dalam tanah yang sebelumnya terisi oleh air sehingga semakin banyak fly ash dimasukan menurunkan kadar air yang ada dalam rongga pori tanah, kadar air menurun mengakibatkankan turunnya batas cair dan turunnya batas cair juga menurunkan indeks plastisitas tanah, karena indeks plastis tanah merupakan pengurangan dari batas cair dengan batas plastis. Pada kondisi awal nilai indeks plastis sebesar 19,72 \%, setelah dicampur dengan fly ash mampu menurunkan hingga menjadi 2,38 \% (pada penambahan FA sebesar 40), hal ini mengindikasikan bahwa tanah yang sudah distabilisasi ini bukan termasuk tanah ekspansif lagi.

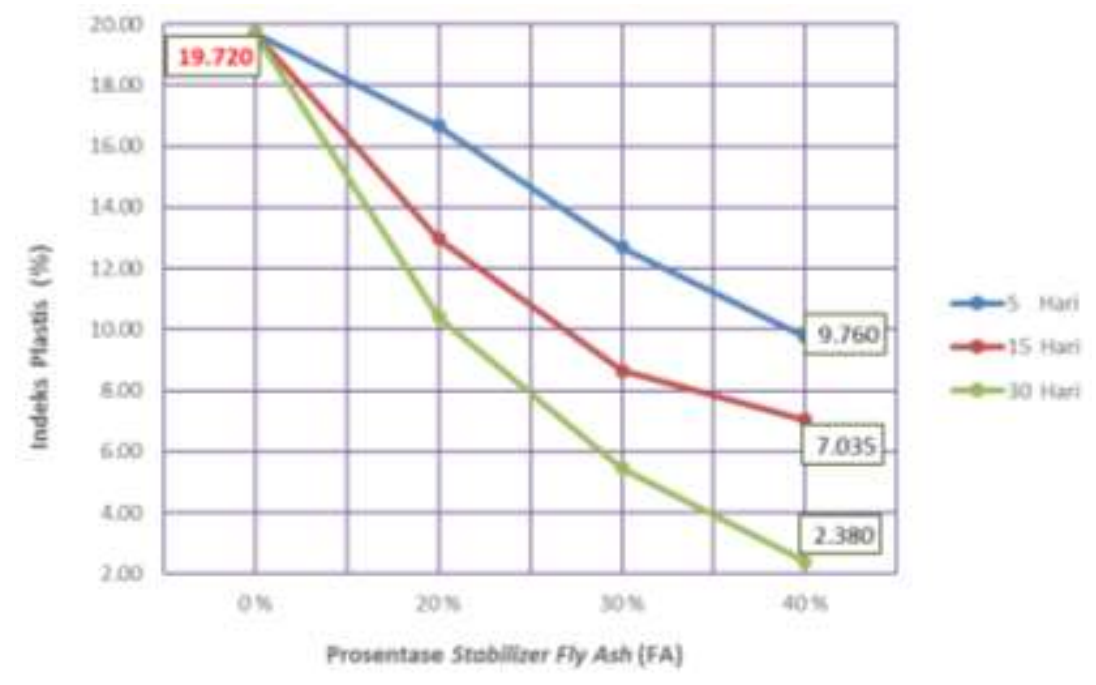

Gambar 4 Grafik Pengaruh Penambahan Stabiliser (FA) terhadap Nilai Indeks Plastis

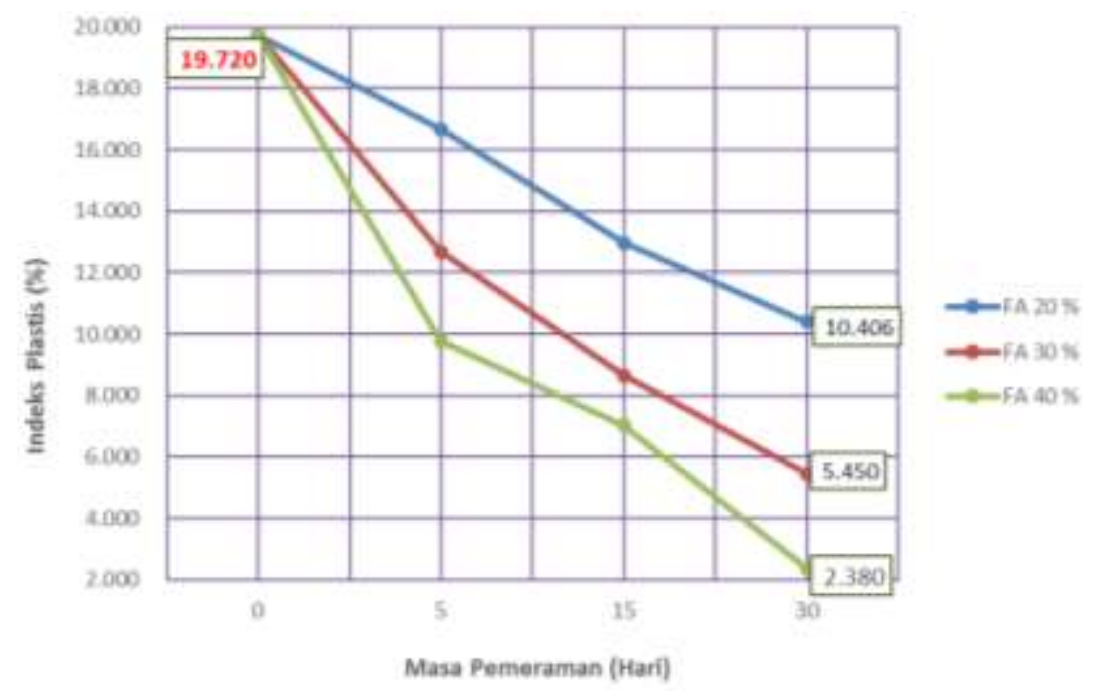

Gambar 5 Grafik Pengaruh Penambahan Masa Peram terhadap Nilai Indeks Plastis

Dari Gambar 5 dapat dilihat kecendrungan penuruan nilai indeks plastis akibat pengaruh bertambahnya masa peram. Penurunan nilai batas cair akibat pengaruh masa peram ini juga menunjukan bahwa proses pozzolonic yang terjadi berlangsung lama sehingga memelukan pemaraman yang cukup lama. Dari hasil pengujian dapat dilihat bahwa pada masa peram selama 30 
hari mampu menurunkan nilai indeks plastis nya sampai menjadi 2,38 \%, hal ini juga mengindentifikasikan bahwa tanah tersebut sudah bukan termasuk tanah ekspansif lagi.

\subsubsection{Uji Sifat Mekanis Tanah Yang Sudah Distabilisasi}

Berat Volume Kering Tanah $\left(\gamma_{\text {dry }}\right)$. Dari pengujian standar proktor di laboratorium, nilai berat volume tanah kering hasilnya disajikan dalam Tabel 1 dan Gambar 6 dan Gambar 7.

Terlihat jelas pada Gambar 6 bahwa penambahan prosentase bahan stabiliser fly ash dapat meningkatkan nilai berat volume kering $\left(\gamma_{d r y}\right)$ tanah ekspansif pada kondisi semua masa peram. Nilai berat volume kering tertinggi diperoleh pada penambahan stabiliser fly ash sebesar $40 \%$ dan pada masa peram 30 hari dengan nilai sebesar $1,31 \mathrm{gr} / \mathrm{cm}^{3}$ (masa peram 5 hari), 1,33 gr/ $\mathrm{cm}^{3}$ (masa peram 15 hari) dan $1,38 \mathrm{gr} / \mathrm{cm}^{3}$ (masa peram 30 hari).

Tabel 1 Nilai Berat Volume Kering hasil uji Pemadatan Tanah

\begin{tabular}{ccccc}
\hline Kode & $\begin{array}{c}\text { Prosentase } \\
\text { Stabilizer } \\
(\mathbf{\%})\end{array}$ & $\mathbf{5}$ & $\mathbf{1 5}$ & $\mathbf{3 0}$ \\
\hline & $\mathbf{0}$ & 1,21 & 1,21 & 1,21 \\
$\mathbf{A}$ & $\mathbf{2 0}$ & 1,25 & 1,26 & 1,23 \\
$\mathbf{B}$ & $\mathbf{3 0}$ & 1,29 & 1,31 & 1,34 \\
$\mathbf{C}$ & $\mathbf{4 0}$ & 1,31 & 1,33 & 1,38 \\
\hline
\end{tabular}

Sumber: Hermiyuniarsi (2020)

Peningkatan nilai berat volume tanah kering ini disebabkan oleh terbentuknya gumpalan padat (CaSiO3) akibat proses kimiawi (pozzolanic) antara kalsium yang ada pada fly ash dan kandungan alumina dan silikat yang ada pada tanah lempung dan juga menyerap air dari rongga pori tanah.

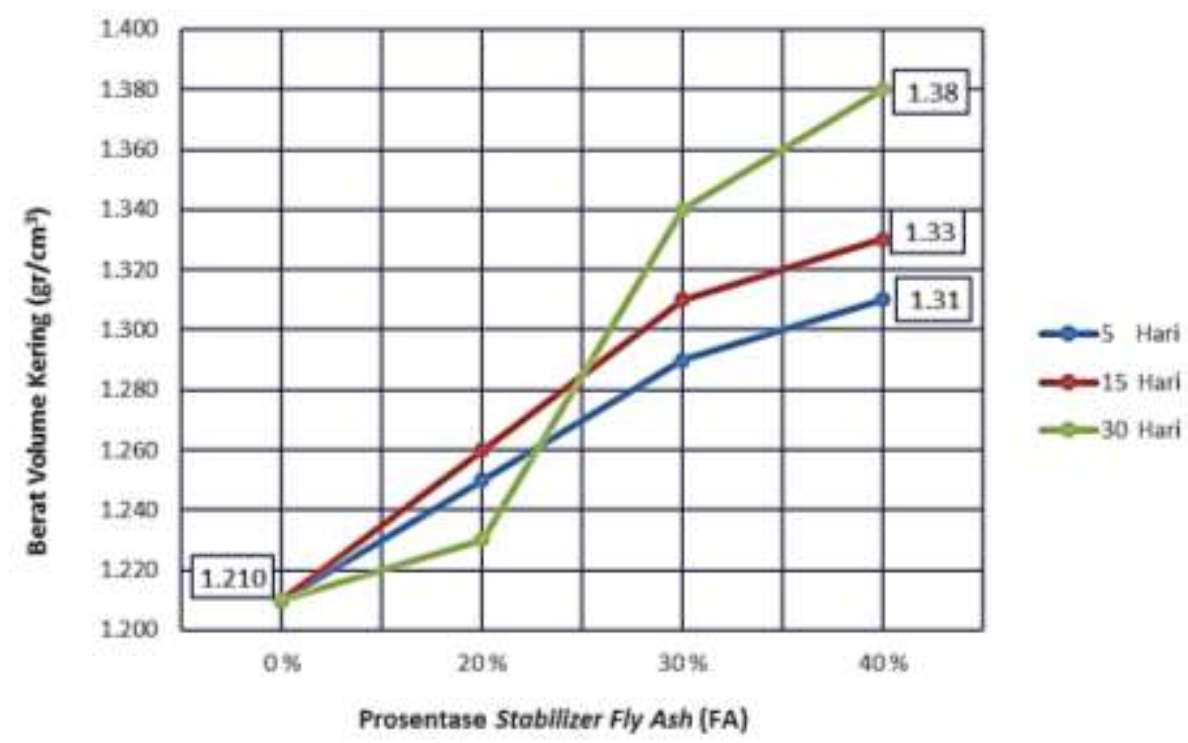

Gambar 6 Grafik pengaruh hubungan antara penambahan prosentase stabiliser (FA) terhadap nilai berat volume kering

Selain itu terjadi proses fisika dimana material fly ash berfungsi sebagai filler yaitu mengisi rongga pori tanah yang tadinya terisi oleh air. Terjadi penyimpangan perilaku disini, yaitu pada pengujian sampel campuran $20 \%$ pada masa peram 30 hari harusnya nilai berat volume tanah keringnya melebihi dari campuran $20 \%$ dengan masa peram 5 hari dan 15 hari, hal ini disebabkan 
kemungkinan pencampuran yang tidak dapat dijamin merata $100 \%$ karena pencampuran/pengadukan dilakukan secara manual sehingga ada sampel yang perilakunya tidak mengikuti trend grafiknya.

Pada Gambar 7 pengaruh masa peram terhadap nilai berat volume kering meningkat yang optimum 30 hari dengan prosenase stabiliser fly ash 20\%, 30\%, dan 40\%, dengan nilai masing - masing sebesar $1,23 \mathrm{gr} / \mathrm{cm}^{3}, 1,34 \mathrm{gr} / \mathrm{cm}^{3}$, dan $1,38 \mathrm{gr} / \mathrm{cm}^{3}$. Peningkatan nilai berat volume tanah kering akibat pengaruh masa peram ini juga menunjukan bahwa proses pozzolonic yang terjadi berlangsung lama sehingga memelukan pemaraman yang cukup lama. Terlihat juga disini akibat pencampuran yang tidak merata $100 \%$ sehingga ada sampel (masa peram 30 hari campuran $20 \%$ fly $a s h$ ) yang perilakunya tidak mengikuti trend grafik seperti parameter-parameter lainnya. Harusnya pada campuran $20 \%$ dengan masa peram 30 hari menghasilkan nilai berat volume tanah keringnya lebih besar dari pada campuran 20\% dengan masa peram 15 hari dan 5 hari.

Berdasarkan Gambar 6 dan Gambar 7 dapat disimpulkan bahwa penambahan stabiliser $40 \%$ dan masa peram 30 hari mampu memberikan peningkatan nilai berat volume tanah kering maksimum sebesar 14,05\% dari kondisi tanah awal/asli (fly ash $=0 \%$ ) sebesar $1,21 \mathrm{gr} / \mathrm{cm}^{3}$ menjadi 1,38 $\mathrm{gr} / \mathrm{cm}^{3}$.

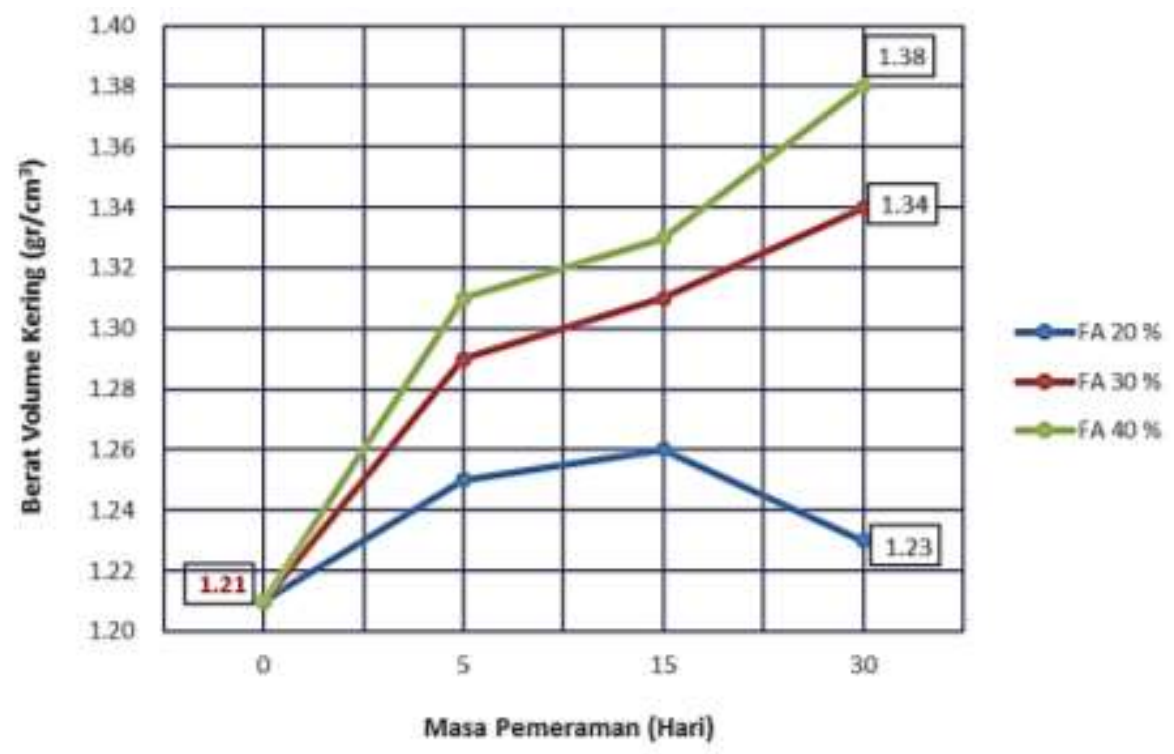

Gambar 7 Grafik hubungan antara penambahan masa peram terhadap nilai berat volume kering

Kadar Air Optimum $\left(\boldsymbol{w}_{\text {opt }}\right.$ ). Dari pengujian standar proktor di laboratorium, nilai berat volume tanah kering hasilnya disajikan dalam Tabel 2 dan Gambar 8 dan Gambar 9.

Tabel 2 Nilai Kadar Air Optimum hasil uji Pemadatan Tanah

\begin{tabular}{ccccc}
\hline Kode & $\begin{array}{c}\text { Prosentase } \\
\text { Stabilizer } \\
(\mathbf{\%})\end{array}$ & $\mathbf{5}$ & $\mathbf{1 5}$ & $\mathbf{3 0}$ \\
\hline & $\mathbf{0}$ & 31,19 & 31,19 & 31,19 \\
$\mathbf{A}$ & $\mathbf{2 0}$ & 29,00 & 26,30 & 27,90 \\
$\mathbf{B}$ & $\mathbf{3 0}$ & 25,80 & 23,90 & 23,70 \\
$\mathbf{C}$ & $\mathbf{4 0}$ & 22,00 & 20,60 & 19,30 \\
\hline
\end{tabular}

Sumber: Hermiyuniarsi (2020) 
Pada Gambar 8 bahwa penambahan prosentase bahan stabiliser fly ash dapat menurun nilai kadar air optimum tanah ekspansif pada kondisi semua masa peram. Nilai kadar air optimum turun diperoleh pada penambahan stabiliser fly ash sebesar $40 \%$ dan pada masa peram 30 hari dengan nilai sebesar 22,00\% (masa peram 5 hari), 20,60\% (masa peram 15 hari) dan 19,30\% (masa peram 30 hari). Hal ini disebabkan terserapnya air pada proses kimiawi (pozzolanic) antara fly ash dan tanah lempung ekspansif sehingga semakin banyak fly ash yang ditambahkan semakin banyak proses pengikatan yang terjadi dan semakin banyak air yang terserap untuk membentuk gumpalan kalsium silikat. Selain itu terjadi juga proses fisika yaitu dngan masuknya fly ash kedalam rongga tanah yang sebelumnya terisi oleh air. Melihat perilaku/trend grafik maka disini terlihat terjadi penyimpangan pada campuran $20 \%$ dan masa peram 15 hari, seharusnya nilainya berada pada antara masa peram 5 hari dan 30 hari pada campuran yang sama yaitu $20 \%$. Hal ini disebabkan karena tidak ada jaminan tercampurnya merata $100 \%$ antara fly ash dan tanah lempung ekspansif karena pencampuran/pengadukan dilakukan secara manual.

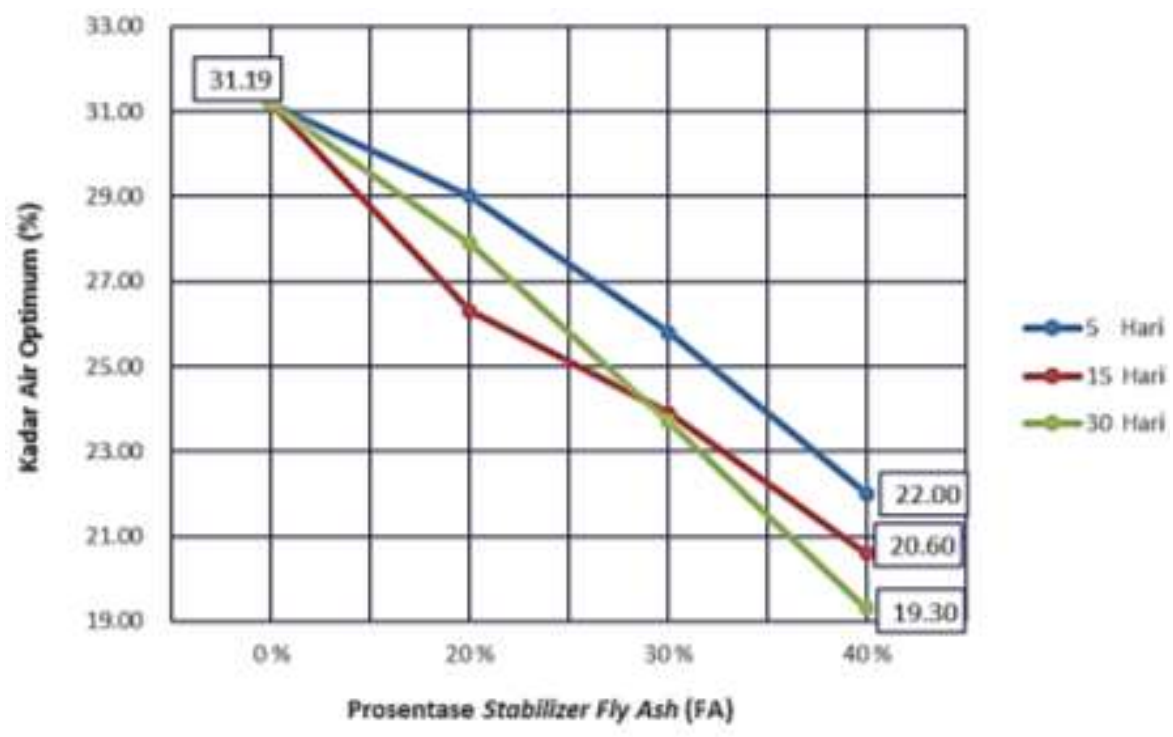

Gambar 8 Grafik hubungan antara penambahan prosentase stabiliser (FA) terhadap nilai kadar air optimum

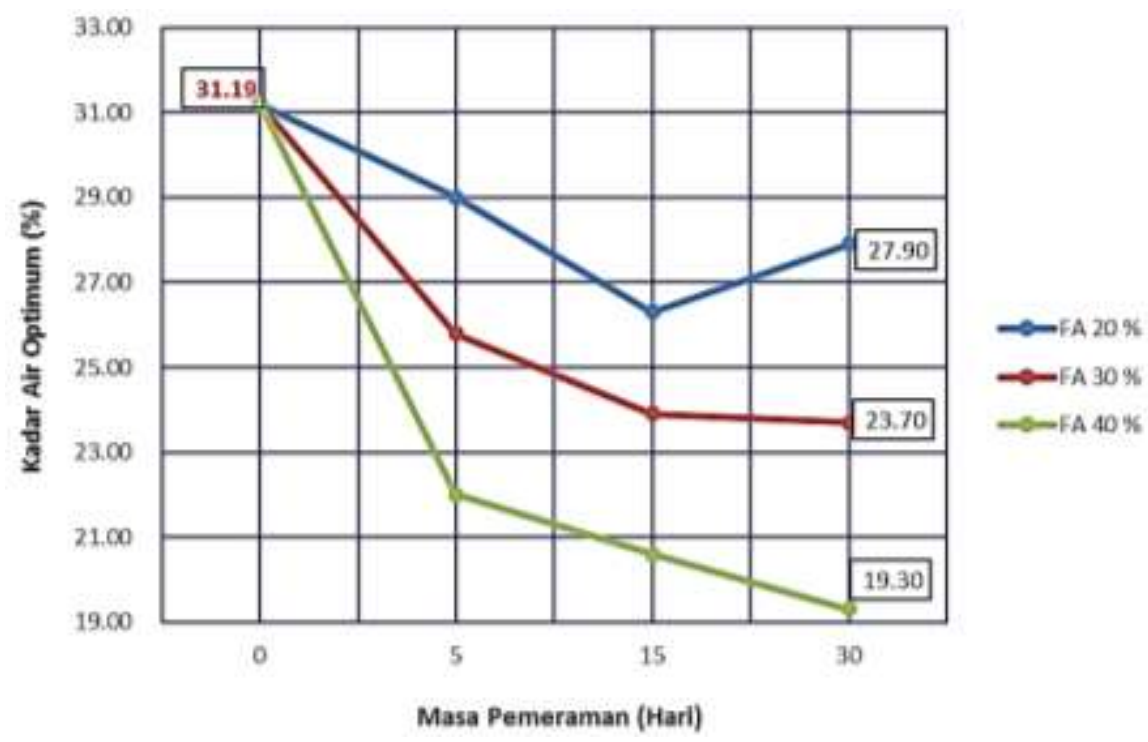

Gambar 9 Grafik hubungan antara penambahan masa peram terhadap nilai kadar air optimum 
Terlihat pada Gambar 9 pengaruh masa peram terhadap nilai kadar air optimum mengalami penurunan yang optimum pada masa peram 30 hari dengan prosentase stabiliser fly ash $20 \%, 30 \%$, dan $40 \%$, dengan nilai masing - masing sebesar 27,90\%, 23,70\%, dan 19,30. Hal ini menunjukan bahwa proses pozzolanic berlangsung lambat sehingga memerlukan waktu yang cukup lama.

Berdasarkan Gambar 8 dan Gambar 9 dapat disimpulkan bahwa penambahan campuran fly ash sebesar $40 \%$ mampu menurunkan kadar air optimum sebesar 38,12 \% dari kondisi tanah asli/awal (fly ash $=0 \%$ ) sebesar 31,19\% menjadi sebesar 19,3\%.

California Bearing Ratio (CBR ). Nilai CBR hasil pengujian di laboratorium dikonversi dan disajikan kedalam CBR $_{\text {Desain }}$ seperti yang ditunjukan dalam Tabel 3, Gambar 10 dan Gambar 11.

Tabel 3 Nilai CBR Desain hasil uji CBR Laboratorium

\begin{tabular}{ccccc}
\hline Kode & $\begin{array}{c}\text { Prosentase } \\
\text { Stabilizer } \\
\mathbf{( \% )}\end{array}$ & $\mathbf{5}$ & $\mathbf{1 5}$ & $\mathbf{3 0}$ \\
\hline & $\mathbf{0}$ & 0,72 & 0,72 & 0,72 \\
$\mathbf{A}$ & $\mathbf{2 0}$ & 2,80 & 6,50 & 14,50 \\
$\mathbf{B}$ & $\mathbf{3 0}$ & 5,10 & 11,30 & 16,50 \\
$\mathbf{C}$ & $\mathbf{4 0}$ & 6,00 & 11,50 & 18,00 \\
\hline
\end{tabular}

Sumber: Hermiyuniarsi (2020)

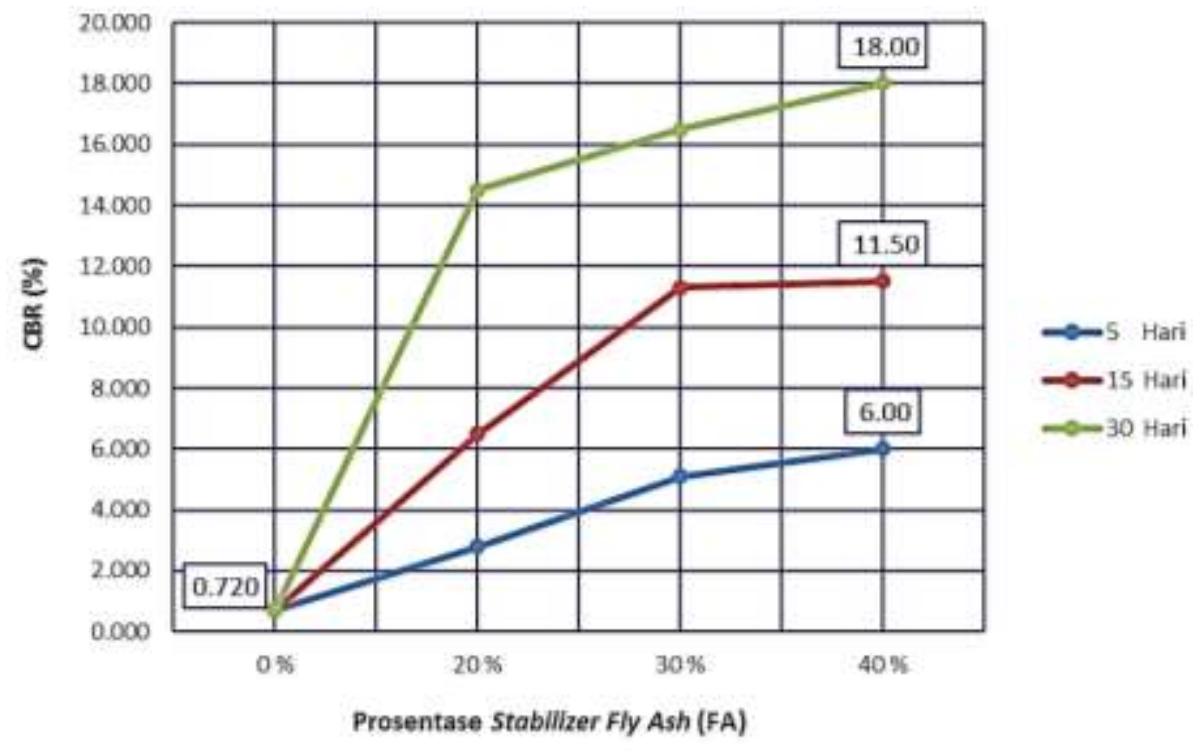

Gambar 10 Grafik hubungan antara penambahan prosentase stabiliser (FA) terhadap nilai CBR Desain $_{\text {}}$

Terlihat jelas pada Gambar 10 bahwa penambahan prosentase bahan stabiliser fly ash dapat meningkatkan nilai $\mathrm{CBR}_{\text {Desain }}$ tanah ekspansif pada kondisi semua masa peram. Peningkatan nilai CBR ini menurut Made Dwika H.P., dkk (2017) karena proses kimiawi (pozzolanic), yaitu reaksi antara kalsium yang terdapat pada fly ash dengan alumina dan silikat yang terdapat pada tanah membentuk gumpalan (CaSiO3) sehingga menghasilkan masa yang keras dan kaku. Penambahan fly ash selain memperkaya kandungan alumina dan silika pada tanah, juga memperbaiki gradasi tanah, rongga pori yang asalnya terisi oleh air dan udara setelah distabilisasi terisi dengan gumpalan padat dan material fly ash yang tidak terikat pada proses kimia mengisi rongga tanah (proses fisika) yang sudah pasti dapat meningkatkan daya dukung tanahnya. Nilai CBR $_{\text {Desain }}$ terus 
meningkat dan diperoleh nilai maksimum pada penambahan stabiliser fly ash sebesar $40 \%$ dan pada masa peram 30 hari dengan nilai sebesar 6\% (masa peram 5 hari), 11,50\% (masa peram 15 hari) dan $18 \%$ (masa peram 30 hari). Kondisi optimum khusus nilai $\mathrm{CBR}_{\text {Desain }}$ terjadi pada penambahan campuran $30 \%$, ketika ditambah lagi menjadi $40 \%$ nilai $\mathrm{CBR}_{\text {Desain }}$ terus meningkat, tetapi tidak signifikan lagi.

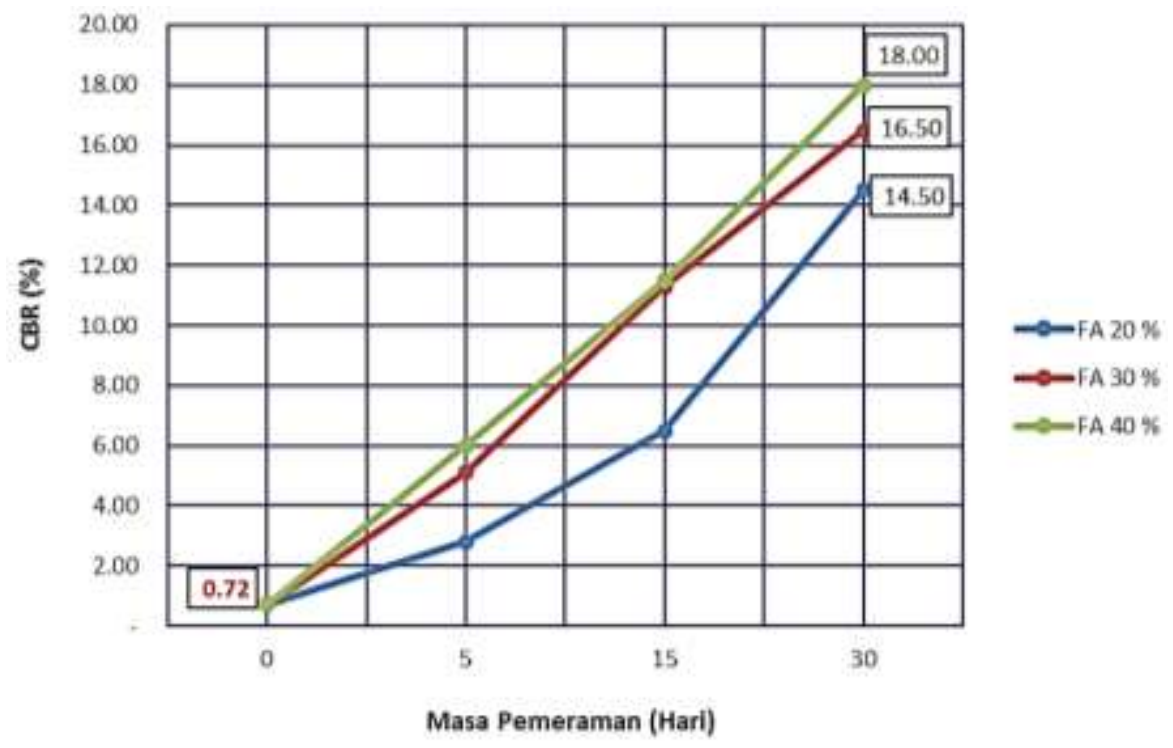

Gambar 11 Grafik hubungan antara penambahan masa peram terhadap nilai $\mathrm{CBR}_{\text {Desain }}$

Dari Gambar 11 terlihat jelas bahwa peningkatan nilai $\mathrm{CBR}_{\text {Desain }}$ semakin signifikan seiring dengan penambahan masa peram dari 5 hari, 15 hari sampai 30 hari, hal ini menunjukan bahwa proses pozzolanic antara bahan stabliser fly ash dan tanah lempung ekspansif memang lambat sehingga memerlukan waktu yang cukup lama. Nilai $\mathrm{CBR}_{\text {Desain }}$ meningkat pada masa peram 30 hari menjadi $18 \%$ (penambahan fly ash 40\%), menjadi 16,5\% (penambahan fly ash $30 \%$ ), dan menjadi $14,5 \%$ (penambahan fly ash 20\%). Dari hasil pengujian ini juga dapat dilihat bahwa masih memungkinkan menambahkan variasi masa peram yang lebih dari 30 hari.

Berdasarkan Gambar 10 dan Gambar 11 dapat disimpulkan bahwa kondisi nilai CBR $_{\text {Desain }}$ maksimum terdapat pada campuran stabiliser fly ash $40 \%$ dengan masa peram 30 hari yaitu peningkatannya sebesar $2400 \%$ dari kondisi tanah asli/awal (fly ash $=0 \%$ ) sebesar $0,72 \%$ menjadi $18 \%$.

\section{Kesimpulan}

Berdasarkan karakteristik dari hasil pengujian sifat fisis tanah di laboratorium diketahui bahwa tanah yang digunakan sebagai penelitian yang berasal dari Daerah Selimau Kabupaten Bulungan adalah tanah ekspansif (expansive soil).

Penambahan bahan material berupa abu terbang batubara (fly ash) sangat berpengaruh pada perilaku teknis tanah ekspansif, hal ini dapat dilihat dari perubahan parameter tanah yang memperlihatkan kecendrung terus meningkat melalui pengujian sifat mekanis dengan uji pemadatan proktor dan uji CBR laboratorium. Nilai berat volume kering tanah $\left(\gamma_{d r y}\right)$ meningkat sebesar 14,05 \%, kadar air optimum $\left(w_{\text {opt }}\right)$ mampu diturunkan sebesar 38,12\% dan $\mathrm{CBR}_{\text {Desain }}$ mampu meningkat signifikan $2400 \%$ pada campuran penambahan fly ash $40 \%$ dan setelah melewati masa peram 30 hari. 


\section{Ucapan Terima Kasih}

Terima kasih yang tidak terhingga disampaikan kepada seluruh staf Laboratorium DPU Kabupaten Bulungan yang menyediakan laboratorium mekanika tanah, PT.PKN yang menyediakan material fly ash, serta Hermiyuniarsi dkk mahasiswa teknik sipil Unikaltar yang melakukan pengambilan sampel dan pengujian di laboratorium.

\section{Daftar Pustaka}

Badan Standarisasi Nasional, 1994. Metode Pengujian Berat Isi Tanah Berbutir Halus Dengan Cetakan Benda Uji (SNI 03-3637-1994). Bandung: BSN.

Badan Standarisasi Nasional, 2008. Cara Uji Kepadatan Ringan Untuk Tanah (SNI 1742:2008). Bandung: BSN.

Badan Standarisasi Nasional, 2008. Cara Uji Penentuan Kadar Air Untuk Tanah dan Batuan di Laboratorium (SNI 1965:2008). Bandung: BSN.

Badan Standarisasi Nasional, 2008. Cara Uji Berat Jenis Tanah (SNI 1964:2008). Bandung: BSN.

Badan Standarisasi Nasional, 2008. Cara Uji Penentuan Batas Cair Tanah (SNI 1967:2008). Bandung: BSN.

Badan Standarisasi Nasional, 2008. Cara Uji Analisis Ukuran Butiran Tanah (SNI 3423:2008). Bandung: BSN.

Badan Standarisasi Nasional, 2008. Cara Uji Penentuan Batas Plastis dan Indeks Plastisitas Tanah (SNI 1966:2008). Bandung: BSN.

Badan Standarisasi Nasional, 2012. Metode Uji CBR Laboratorium (SNI 1744:2012). Bandung: BSN.

Budi, Setyo Gogot, dkk. 2003. Pengaruh Fly Ash Terhadap Sifat Pengembangan Tanah Ekspansif. Jurnal Civil Engineering Dimension, Vol. 5, No. 1: ISSN 1410-9530.

Denny, B. Pinasang, dkk., 2016. Analisis Campuran Kapur-Fly Ash Dan Kapur-Abu Sekam Padi Terhadap Lempung Ekspansif. Jurnal Ilmiah Media Engineering, Vol.6 No.3: ISSN 20879334.

Ernawan S., dkk., 2018. Pengaruh Bahan Tambah Fly Ash Terhadap Karakteristik Tanah Lempung Ekspansif Di Daerah Dringu Kabupaten Probolinggo. Media Teknik Sipil Vol. 16 No.1: ISSN 1693-3095.

Gunarso, A., 2017. Stabilisasi Tanah Lempung Ekspansif Dengan Campuran Larutan NaOH. Jurnal Karya Teknik Sipil Vol.6 No.2: http://ejournal-s1.undip.ac.id/index.php/jkts

Hardiyatmo, H.C., 2014. Tanah Ekspansif Permasalahan dan Penanganan. Yogyakarta: Gadjah Mada University Press.

Herman, 2013. Abu Batubara PLTU Sijantang Sebagai Bahan Stabilisasi Tanah Lempung Ekspansif. Jurnal vol. 15 No.2: ISSN 169-752X.

Herman, dkk., 2014. Pengaruh Abu Batubara dan Kapur Terhadap Kembang Susut Tanah Lempung Pada Kondisi Basah Optimum. Jurnal Momentum Vol.16 No.1: ISSN 1693-752X 
I Gusti Agung. 2014. Karakteristik Tanah Lempung Ekspansif (Studi Kasus di Desa Tanah Awu, Lombok Tengah). GaneÇ Swara. Vol. 8 No.2.

Made Dwika Hutama Putra, dkk., 2017. Pengaruh Perbaikan Tanah Lempung Ekspansif Dengan Metode Deep Soil Mixing pada Berbagai Kadar Air Lapangan Tanah Asli Terhadap Nilai CBR dan Pengembangan. https://www.neliti.com/publications/116101

Sudjianto, dkk., 2006. Pengaruh Matric Suction Terhadap Perilaku Kembang Bebas Tanah Lempung Ekspansif. Jurusan Teknik Sipil Fakultas Teknik Universitas Widyagama Malang.

Sudjianto, 2015. Tanah Ekspansif; Karakteristik dan Pengukuran Perubahan Volume. Yogyakarta: Graha Ilmu.

Walewangko B.Y., 2020. Pengaruh Penambah Fly Ash dan Trans Pada Tanah Lempung Terhadap Nilai CBR. Jurnal Sipil Statik Vol.8 No.1: ISSN 2337-6732. 